\title{
Microvascular obstruction is associated with greater infarct heterogeneity
}

\author{
Idan Roifman ${ }^{1 *}$, Nilesh R Ghugre', Mohammad I Zia', Alexander W Leber ${ }^{1}$, Anna Zavodni ${ }^{1}$, Kim A Connelly ${ }^{2,1}$, \\ Graham Wright ${ }^{1}$
}

From 16th Annual SCMR Scientific Sessions

San Francisco, CA, USA. 31 January - 3 February 2013

\section{Background}

Microvascular obstruction (MVO) has been shown to be an independent predictor of left ventricular dysfunction and death. Infarct heterogeneity as measured by gray zone has been shown to be an independent predictor of post infarct mortality. We sought to compare the evolution of gray zone in patients with and without MVO.

\section{Methods}

21 patients post primary percutaneous coronary intervention for acute ST elevation myocardial infarction were prospectively enrolled and each had 3 MRI scans on a 1.5T GE Signa Excite scanner at 48 hours, 3 weeks and 6 months post infarction. A T1-weighted IR-GRE sequence was used for late gadolinium enhancement assessment of infarcted myocardium. Core infarct size (CIS) and gray zone (GZ) volumes were quantified using the full width at half-maximum technique and were expressed in grams. Repeated Measures Analysis of Variance was used to assess for changes in CIS and GZ evolution over the three time frames. Data is presented as means \pm standard deviation at the 48 hour, 3 week and 6 month time frames respectively.

\section{Results}

Of the 21 patients, 9 had evidence of MVO and $12 \mathrm{did}$ not. Mean age was $57.7 \pm 10.3$ years. 19/21 of the patients were male. 8 of the infarcts involved the left main/left anterior descending artery, 5 involved the left circumflex artery and 8 involved the right coronary artery. Both MVO $(29.6 \pm 11.5$ g, $15.9 \pm 5.6$ g, $15.2 \pm 7.39$ g , p <0.01) and non-MVO $(9.4 \pm 7.7 \mathrm{~g}, 5.5 \pm 4.05 \mathrm{~g}, 4.1 \pm 3.5 \mathrm{~g}$,

\footnotetext{
${ }^{1}$ Medicine, Imaging Research Centre for Cardiac Interventions, Schulich Heart Centre, Sunnybrook Health Sciences Centre, University of Toronto, Toronto, ON, Canada

Full list of author information is available at the end of the article
}

$\mathrm{p}=0.01)$ patients had a significant decrease in core infarct size over the three time frames. Patients with MVO did not have a significant change in gray zone across the three time points $(11.5 \pm 5.4 \mathrm{~g}, 10.2 \pm 7.4 \mathrm{~g}$ and $10.9 \pm 7.5 \mathrm{~g}$, $\mathrm{p}=0.83$, see figure 1$)$. In contrast, non-MVO patients did have a significant decrease of gray zone over time (6.9 $\pm 6.5 \mathrm{~g}, 3.8 \pm 3.38 \mathrm{~g}, 2.5 \pm 2.93 \mathrm{~g}, \mathrm{p}<0.01$, see figure 2 ).

\section{Conclusions}

In contrast to those patients without MVO, patients with MVO did not exhibit a significant reduction in GZ. As GZ has been shown to be associated with arrhythmic events, its relative persistence over time in the presence of MVO may partially explain the mechanism leading to the poorer prognosis of MVO.

\section{Funding}

Heart and Stroke Foundation of Canada.

Ontario Research Fund.

Canadian Institutes of Health Research.

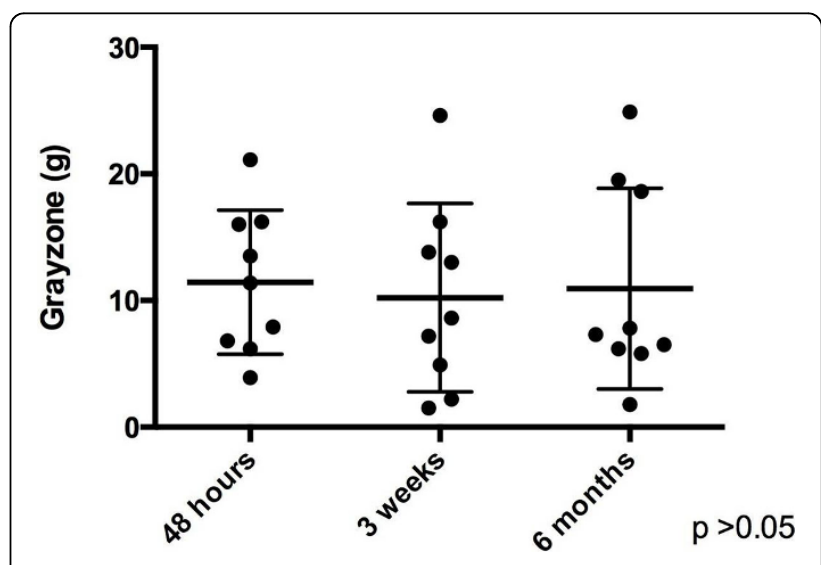

Figure 1 Evolution of gray zone in MVO patient $\mathrm{s}$.

\section{C)

(0) 2013 Roifman et al; licensee BioMed Central Ltd. This is an Open Access article distributed under the terms of the Creative Commons Attribution License (http://creativecommons.org/licenses/by/2.0), which permits unrestricted use, distribution, and reproduction in any medium, provided the original work is properly cited. 


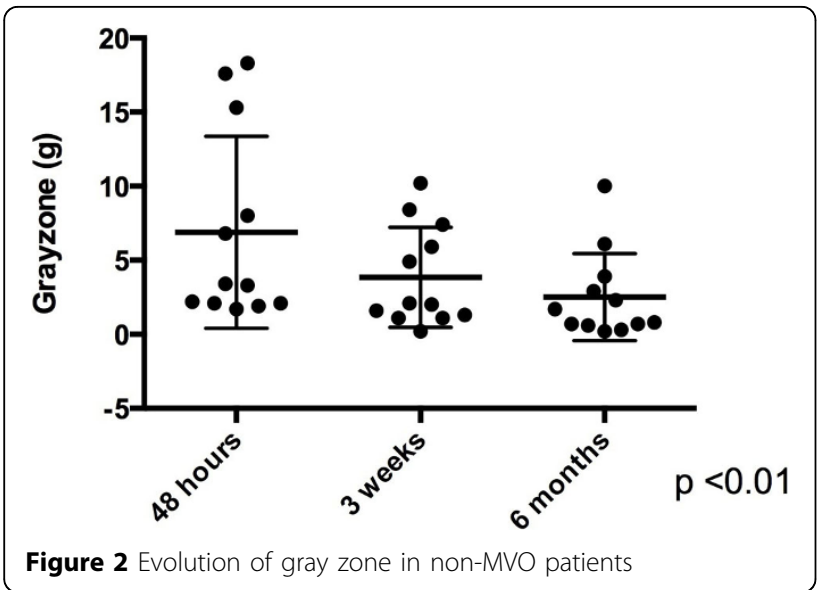

\section{Author details}

'Medicine, Imaging Research Centre for Cardiac Interventions, Schulich Heart Centre, Sunnybrook Health Sciences Centre, University of Toronto, Toronto, ON, Canada. ${ }^{2}$ Medicine, St. Michael's Hospital, University of Toronto, Toronto, ON, Canada.

Published: 30 January 2013

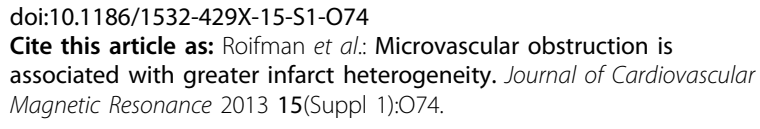

Submit your next manuscript to BioMed Central and take full advantage of:

- Convenient online submission

- Thorough peer review

- No space constraints or color figure charges

- Immediate publication on acceptance

- Inclusion in PubMed, CAS, Scopus and Google Scholar

- Research which is freely available for redistribution

Submit your manuscript at www.biomedcentral.com/submit 